\title{
Influence of the orientation of uterine bulbs during planting on the seed yield of winter onion variety Ellan in a two-yield direct crop
}

\author{
Victor Lazko and Olga Yakimova* \\ Federal Scientific Rice Centre, Belozerny, 3, Krasnodar, 350921, Russian Federation
}

\begin{abstract}
The article presents the results on the use of paracuneal bulbs for re-harvesting seeds in a direct crop. The influence of the orientation of uterine bulbs during planting on the formation of paracuneal bulbs and seed productivity in the second year of vegetation was determined. The paracuneal bulbs were developing at the base of the flower shoots maintaining the same orientation as in the uterine bulbs when planted. Winter hardiness of paracuneal bulbs depended on orientation, just as with standard technology. Losses during the winter period ranged from $48 \%$ to $82 \%$, increasing with an increase in the angle of deviation from the vertical position. The most vulnerable bulbs were the upside down. Paracuneal bulbs can be used to re-harvest seeds in a two-yield crop.
\end{abstract}

\section{Intoduction}

In the context of a shortage of seeds of domestic onion varieties, it is necessary to develop methods for increasing the efficiency of seed production to meet the need for seeds. When growing seeds, the winter onion variety Ellan simultaneously forms paracuneal bulbs. The yield of paracuneal bulbs, depending on the size of the used planting material and the layout, can reach up to $12.6 \mathrm{t} /$ ha $[1,4]$.

One of the energy-saving and economically profitable directions, especially for the rapid reproduction of a scarce variety, is the use of paracuneal bulbs for re-growing seeds in a direct way (bivoltine crop) or transplanting paracuneal bulbs to a new site, for a single reproduction of seeds in addition to the main method of seed production $[2,4,5]$.

The most labor-consuming technology element in onion seed production is planting. The uterine bulbs are planted by hand in furrows or mechanically. When mechanized planting of onion mother plants with a potato planter without manual orientation, more than $70 \%$ of the bulbs lie in the planting furrow at different angles and upside down $[8,9]$. The orientation of the bulbs during planting affects not only winter hardiness, plant development and seed productivity, but also the formation of paracuneal bulbs and the future yield. During the growing season, with the growth of paracuneal bulbs, the same orientation is maintained as in the planted mother plants (Fig. 1) [5].

\footnotetext{
*Corresponding author: belyaeva12092013@yandex.ru
} 
The aim of the study is to study the influence of the orientation of uterine bulbs during planting on the characteristics of growth, development and seed productivity of paracuneal bulbs in a two-yield direct crop.

\section{Materials and methods}

The research was carried out in the department of vegetable and potato growing of FSBSI "Federal Scientific Rice Centre" according to generally accepted methods [6]. Uterine bulbs of an early winter short-day onion variety Ellan of medium size (diameter 4-6 cm) were planted in October 2013 and 2014 in pre-cut furrows to a depth of $12-15 \mathrm{~cm}$. Planting scheme - $0.7 \times 0.1 \mathrm{~m}$. Planting density - 143 thousand pieces / ha . The accounting area of the plot is $7 \mathrm{~m}^{2}$. The repetition is fivefold. The technology of growing onion seeds is common in Krasnodar region for onion varieties [2, 3].

Experiment options: vertical planting- $0^{\circ}$, at an angle of $45^{0}$ (sideways), horizontally at an angle of $90^{\circ}$ and upside down $-180^{\circ}$.

During the growing season, phenological and biometric observations and counts were carried out. The harvesting of seed plants was started when there were $15 \ldots 20 \%$ of inflorescences with open bolls and was performed manually by counting the number of inflorescences with open bolls (harvesting ripeness), cut umbels and harvested plants. Inflorescences without peduncles were cut off. Threshed after ripening and drying, then the seeds were washed in water and dried.

The physical and sowing qualities of seeds were determined according to the method used by state control and seed laboratories (GOST 32592 - 2013, GOST 12038-84, 1204182, 12042-80).

During the harvesting period, the seedstalks are still green (Fig. 2). Two weeks after harvesting the inflorescences, the seedstalks were mowed at the soil surface (Fig. 3). During this time, there was an outflow of nutrients from the drying seedstalks into the paracuneal bulbs. Paracuneal bulbs were left in the soil to obtain seeds for the next year in a two-yield direct crop.

\section{Paracuneal bulbs left in the winter for a second yield}

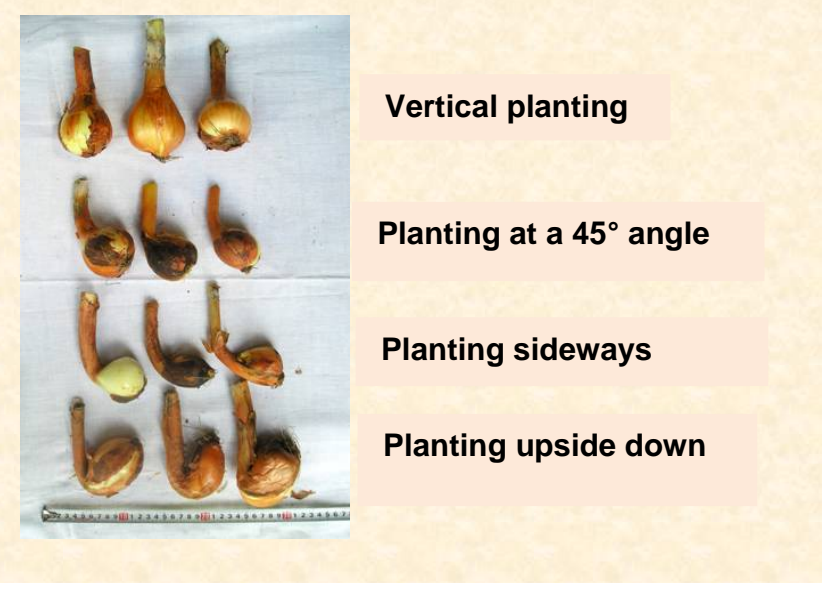

Fig. 1. Paracuneal bulbs left in the winter for a second yield 


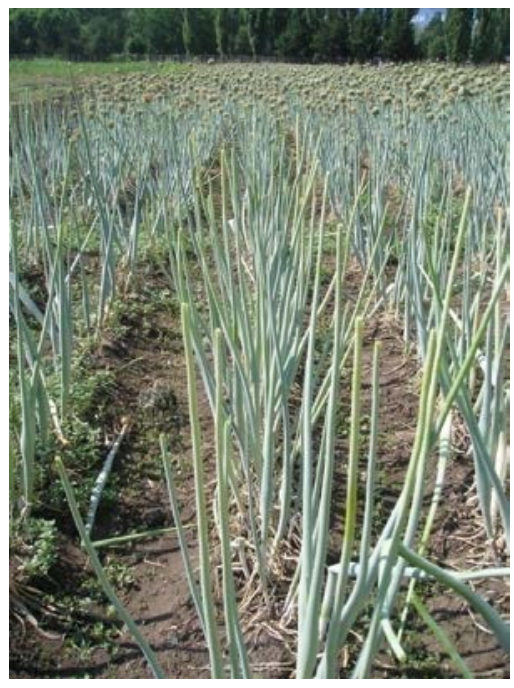

Fig. 2. Green seedstalks after cutting the inflorescences, July 2014.

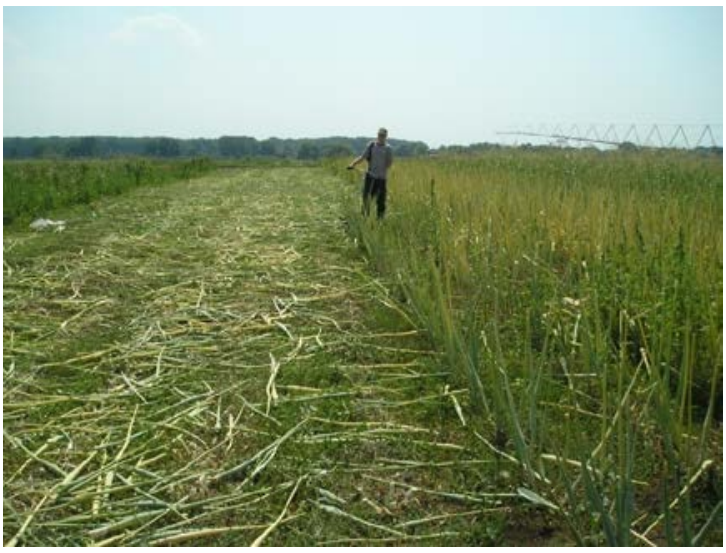

Fig. 3. Mowing seedstalks near the soil surface, August 2015

\section{Results}

The orientation of the bulbs during planting influenced the formation of paracuneal bulbs. In the first year of the growing season, during the growth of paracuneal bulbs, the same orientation is maintained as in the planted mother plants (Fig. 1).

At the end of September, after the harvesting and mowing of the dried seedstalks, the leaves of the paracuneal bulbs began to grow back. By winter, the plants had a welldeveloped leaf mass, consisting of $6 \ldots 16$ leaves, with an area of $150 \ldots 230 \mathrm{~cm}^{2}$. A decrease in temperature below $-5 \ldots-10^{\circ} \mathrm{C}$ promoted freezing of leaves and partial death of plants, especially those planted upsidedown, since the growth zone (bottom) and the root system turned out to be close to the soil surface. Growth processes in autumn led to the depletion of open juicy scales of paracuneal bulbs for the formation of a leaf apparatus and root system, which was one of the factors that reduce their winter hardiness [2,9].

In the second year in spring, the regrowth of leaves began in the first decade of March. Leaves appeared later on the bulbs planted upside down, as in the first year of the growing 
season. The subsequent phases of growth and development occurred simultaneously in all variants.

In the second year of growing the seed plants, the orientation of onion mother plants during planting did not affect the biometric parameters of seedstalks and inflorescences. The height of the peduncles and the diameter of the inflorescences in the phase of wax ripeness of seeds in plants of all variants were practically the same (Table 1). In comparison of the parameters of the seedstalks at one-year cultivation and by the direct method in the second year, the height of the flowering shoots is 6.6 ... 26.4\% higher.

Table 1. The height of the seedstalks and the diameter of the inflorescence in the phase of wax ripeness of seeds, (two-yield direct crop), 2015-2016

\begin{tabular}{|c|c|c|c|c|}
\hline \multirow[t]{2}{*}{ Variant } & \multicolumn{2}{|c|}{ Height of the seedstalks, cm } & \multicolumn{2}{|c|}{$\begin{array}{c}\text { Diameter of the inflorescence, } \\
\mathrm{cm}\end{array}$} \\
\hline & mean value & min.-max. & mean value & min.-max. \\
\hline \multicolumn{5}{|c|}{2015 (planted in 2013) } \\
\hline vertical & 108 & $85-135$ & 8,2 & $7-10$ \\
\hline at $45^{0}$ angle & 117 & $95-130$ & 8,3 & $6-10$ \\
\hline horizontal & 108 & $95-120$ & 8,2 & $7-10$ \\
\hline upside down & 112 & $95-127$ & 8,4 & $8-9$ \\
\hline \multicolumn{5}{|c|}{2016 (planted in 2014) } \\
\hline vertical & 101 & $84-109$ & 8,4 & $7-10$ \\
\hline at $45^{0}$ angle & 106 & $90-115$ & 8,4 & $7-11$ \\
\hline horizontal & 110 & $95-128$ & 8,2 & $8-11$ \\
\hline upside down & 113 & $97-132$ & 8,4 & $6-9$ \\
\hline
\end{tabular}

The seed yield per hectare directly depended on the number of preserved plants (correlation coefficient $r=0.99$ ) and seed productivity of each plant (correlation coefficient $r=0.86-0.97$ ). In a two-yield crop, from 18 to $58 \%$ of the plants planted in the first year were preserved for harvesting. Most of the dyewoods were in the area where the onion mother plants were planted upside down. When the bulb was placed upside down, the inverted growth points turned out to be at the height of the bulb closer to the soil surface under a smaller layer and were more influenced by negative temperature factors in winter. The stringy roots did not have the ability to retract and firmly hold the bulb in the soil due to the wrong orientation in the soil horizon. The root system was damaged and froze, the bulbs were easily detached from the roots or their bottom was mechanically destroyed and subsequently "bulged" to the surface when the soil froze.

Orientation of uterine bulbs horizontally, at an angle and sideways when planting in a two-yield direct crop had practically no effect on the number of seedstalk per plant, seed productivity of seedstalks and plants [2,9] (Table 2). These figures are significantly lower only in the fourth variant, where the bulbs were planted upside down.

In general, the yield with a direct crop is higher by 11.6 ... 48.9\% in comparison with the standard technology of seed production. By the end of the first growing season, paracuneal bulbs developed at the base of the seedstalk. In the cavity, two or more bulbs were formed, each of them grew from two or more flowering shoots. Despite the dyewoods, the number of seedstalks per hectare increased, on which larger inflorescences formed. In the second year, the yield with direct seed production, as with the standard technology, depended on the orientation during the formation of bulbs and naturally decreased with an increase in the angle of deflection. 
Table 2. Seed productivity of onions in direct seed production (two-yield crop), 2015-2016

\begin{tabular}{|c|c|c|c|c|c|c|}
\hline \multirow{3}{*}{ Variant } & \multirow{2}{*}{\multicolumn{2}{|c|}{$\begin{array}{l}\text { Harvested plants to } \\
\text { the planted ones, ha }\end{array}$}} & \multirow{3}{*}{$\begin{array}{l}\text { Number of } \\
\text { seedstalks } \\
\text { per plant, } \\
\text { pcs. }\end{array}$} & \multicolumn{3}{|c|}{ Mass of seeds } \\
\hline & & & & \multirow{2}{*}{$\begin{array}{c}\text { on the } \\
\text { seedstalk, g }\end{array}$} & \multirow{2}{*}{$\begin{array}{l}\text { on the } \\
\text { plant, } g\end{array}$} & \multirow{2}{*}{ kg/ha } \\
\hline & $\%$ & thous.pcs. & & & & \\
\hline \multicolumn{7}{|c|}{2015 (planted in 2013) } \\
\hline vertical & 58 & 83 & 2,4 & 5,1 & 12,2 & $\begin{array}{c}1010 / 75 \\
8\end{array}$ \\
\hline at $45^{0}$ angle & 54 & 77 & 2,4 & 5,1 & 12,2 & $940 / 590$ \\
\hline horizontal & 36 & 52 & 2,4 & 5,3 & 12,6 & $650 / 379$ \\
\hline upside down & 18 & 25 & 1,7 & 5,0 & 8,3 & $210 / 186$ \\
\hline $\mathrm{LSD}_{05}$ & & & & 0,5 & 0,8 & $75 / 72$ \\
\hline \multicolumn{7}{|c|}{2016 (planted in 2014) } \\
\hline vertical & 54 & 78 & 2,5 & 4,9 & 11,2 & $917 / 657$ \\
\hline at $45^{0}$ angle & 49 & 70 & 2,4 & 4,9 & 10,9 & $842 / 563$ \\
\hline horizontal & 40 & 64 & 2,4 & 4,8 & 11,0 & $661 / 355$ \\
\hline upside down & 22 & 28 & 1,8 & 4,6 & 7,6 & $352 / 180$ \\
\hline $\mathrm{LSD}_{05}$ & & & & 0,4 & 0,9 & $77 / 35$ \\
\hline
\end{tabular}

\section{Two-yield direct crop/standard technology}

It was noted that for two years of research the seed yield from near-arrow bulbs without replanting was higher than in the first year of the study. This is due to the fact that the components of plant productivity are higher with a two-yield direct crop. So, on larger inflorescences, flowers were set 1.4-2 times more and bolls - 2.2-2.4 times. The analysis of the inflorescences structure demonstrates how the orientation of bulbs planting influenced the indicators of the second yield of seeds. With an increase in the angle of deflection, the number of flowers in the inflorescence decreased by 17.8 ... 29.6\% and the number of bolls set by $14.8 \ldots 17.2 \%$. Over the years of research, from $66.2 \%$ to $72.7 \%$ of flower bolls were set in the inflorescence. No more than 2.9 seeds ripened in a boll. The potential productivity of onion seed plants was realized by 29.7 ... 34.7\% (Table 3). The physical and sowing qualities of onion seeds in a two-yield crop were at the level of the first class seeds and suitable for the commercial production of onions.

Table 3. Yield structure of one onion inflorescence depending on the orientation of the mother plants when planting in 2013-2014, (two-yield crop, no transplantation), 2015-2016.

\begin{tabular}{|c|c|c|c|c|c|c|}
\hline \multirow{3}{*}{ Indicator } & \multicolumn{6}{|c|}{ Orientation of the bulbs } \\
\hline & \multicolumn{2}{|c|}{ vertical } & \multicolumn{2}{|c|}{ at $45^{0}$ angle } & \multicolumn{2}{|c|}{ horizontal } \\
\hline & 2015 & 2016 & 2015 & 2016 & 2015 & 2016 \\
\hline Total number of flowers, pcs. & 936 & 870 & 794 & 710 & 722 & 685 \\
\hline $\begin{array}{l}\text { Total number of bolls: pcs. } \\
\% \text { from flowers }\end{array}$ & $\begin{array}{l}620 \\
66,2\end{array}$ & $\begin{array}{l}580 \\
66,7\end{array}$ & $\begin{array}{l}538 \\
67,8\end{array}$ & $\begin{array}{l}505 \\
71,1\end{array}$ & $\begin{array}{l}529 \\
72,6\end{array}$ & $\begin{array}{l}498 \\
72,7\end{array}$ \\
\hline Seeds on inflorescence, pcs. & 1680 & 1550 & 1600 & 1480 & 1390 & 1270 \\
\hline Mass of seeds on inflorescence, $\mathrm{g}$ & 5,1 & 4,9 & 5,3 & 4,9 & 5,0 & 5,0 \\
\hline Mass of 1000 seeds, $\mathrm{g}$ & 3,5 & 3,7 & 3,9 & 3,7 & 3,6 & 3,6 \\
\hline Seeds in one boll, pcs. & 2,7 & 2,7 & 2,9 & 2,9 & 2,6 & 2,6 \\
\hline $\begin{array}{l}\text { Seeds in \% to their potential number: } \\
\text { in bolls } \\
\text { in flowers }\end{array}$ & $\begin{array}{l}45,2 \\
30,0\end{array}$ & $\begin{array}{l}45,0 \\
29,7\end{array}$ & $\begin{array}{l}49,5 \\
33,6\end{array}$ & $\begin{array}{l}48,3 \\
34,7\end{array}$ & $\begin{array}{l}43,8 \\
31,8\end{array}$ & $\begin{array}{l}43,3 \\
30,9\end{array}$ \\
\hline
\end{tabular}


After harvesting, the seedstalks were dried, thereby ensuring the outflow of plastic substances into the paracuneal bulbs and then mowing. The yield of paracuneal bulbs over the years of research amounted to 3.9 ... 4.9 t / ha. Despite the dyewoods, it significantly exceeded the planting rate. The increase was due to the branching of the uterine bulb and the formation of a paracuneal bulb at the base of each flower shoot. Instead of one planted bulb, by the end of the second year of the growing season, an average of 1.4 to 2.7 pieces were formed. Some cavities contain up to 6 bulbs (Table 4). The orientation of the uterine bulbs during planting significantly influenced the number of paracuneal bulbs. By the end of the second year of the growing season, the maximum amount was with vertical planting and decreased with an increase in the orientation angle. It directly depended on the dyewoods for two winters $(r=0.94 \ldots 0.99)$ and the number of seedstalks on one plant $(r=$ 0.94 ... 0.98).

With a shortage of planting material and rapid multiplication of the variety, these bulbs can be used as planting material, leaving it without transplanting for the third year or used to set up a seed plot in a new place.

Table 4. Yield and parameters of paracuneal bulbs, 2015-2016 (planted in 2013-2014).

\begin{tabular}{|c|c|c|c|c|c|c|}
\hline \multirow{3}{*}{ Variant } & \multicolumn{6}{|c|}{ Bulbs } \\
\hline & \multicolumn{2}{|c|}{ per one plant, pcs. } & \multicolumn{2}{|c|}{ mass, $g$} & \multirow{2}{*}{$\begin{array}{l}\text { per } 1 \text { ha, } \\
\text { thous. pcs. }\end{array}$} & \multirow{2}{*}{ yield, t/ha } \\
\hline & from-to & mean value & from-to & mean value & & \\
\hline & \multicolumn{6}{|c|}{2015 (planted in 2013) } \\
\hline vertical & $1-5$ & 2,7 & $48-97$ & 56 & 77,1 & 4,3 \\
\hline at $45^{0}$ angle & $1-6$ & 2,5 & $53-116$ & 68 & 71,4 & 4,9 \\
\hline horizontal & $1-6$ & 2,4 & $56-88$ & 67 & 68,5 & 4,6 \\
\hline \multirow[t]{2}{*}{ upside down } & $1-4$ & 1,5 & $35-93$ & 53 & 42,8 & 4,0 \\
\hline & \multicolumn{6}{|c|}{2016 (planted in 2014) } \\
\hline vertical & $1-4$ & 2,5 & $44-108$ & 59 & 74,5 & 4,4 \\
\hline at $45^{\circ}$ angle & $1-6$ & 2,5 & $50-120$ & 65 & 70,2 & 4,7 \\
\hline horizontal & $1-4$ & 2,2 & $41-111$ & 60 & 64,4 & 4,3 \\
\hline upside down & $1-4$ & 1,4 & $33-82$ & 58 & 41,2 & 3,9 \\
\hline \multicolumn{7}{|c|}{ For number of bulbs $\mathrm{F}_{\text {fact. }} 47,59>\mathrm{F}_{\text {theor }} 4,26$} \\
\hline \multicolumn{5}{|c|}{ For mass of bulbs $F_{\text {fact. }} 8,56>F_{\text {theor. }} 4,26$} & & \\
\hline \multicolumn{3}{|c|}{ For yield $F_{\text {fact. }} 14,21>F_{\text {theor. }} 4,26$} & \multicolumn{2}{|c|}{$\mathrm{LSD}_{05}=0,6$} & & \\
\hline
\end{tabular}

\section{Conclusions}

1. The orientation of the uterine bulbs during planting affects the orientation during the growth of paracuneal bulbs, which repeats the same angle of inclination during formation.

2. Dyewoods in winter in the second year of the growing season range from 48 to $82 \%$, increasing with an increase in the angle of deviation from the vertical position. A decrease in the number of initially planted plants is compensated by an increase in the number of paracuneal bulbs due to branching. For harvesting, the number of plants is from 25 to 83 thousand pieces / ha. Each bulb grows on average 1.5 ... 2.7 seedstalks.

3. Seed yield with a non-transplanting two-yield cultivation method is not inferior to the standard cultivation technology and is even higher by $11.6 \ldots 48.9 \%$ than with the standard technology. The maximum seed yield of 917 ... $1010 \mathrm{~kg}$ / ha was obtained from paracuneal bulbs, which were formed from mother plants planted vertically.

4. It was found that to obtain a second yield of seeds from paracuneal bulbs without transplanting, using mechanized planting of mother plants with a potato planter, it is necessary to manually orient the bulbs, which ensures the maximum seed yield. 


\section{References}

1. E.N. Blagorodova, Potato and vegetables, № 3, 7-8, (2002)

2. E.N. Blagorodova, V.E. Lazko, Guidelines on cultivation and seed production of winter onion varieties in Kuban, 39, (2008)

3. R.A. Gish, G.S. Gikalo, Vegetable growing in the South of Russia, 632, (2012)

4. V.E. Lazko, Coll. Issues of scientific support of vegetable growing in the South of Russia, 105-112, (2009)

5. V.E. Lazko, Coll. Issues of scientific support of vegetable growing in the South of Russia, 113-120, (2009)

6. S.S. Litvinov, Methods of experimental work in vegetable growing, 648, (2011)

7. V.F. Pivovarov, I.I. Ershov, A.F. Agafonov, Onion crops, 500, (2001)

8. I.P. Prokhorov, Proceedings of MTAA, № 179, 69-73, (1972)

9. M.I. Sazonov, Collection of works, №2, 19-34, (1972) 